\title{
Measurement of International Roughness Index by Using Z-Axis Accelerometers and GPS
}

\author{
Yuchuan Du, Chenglong Liu, Difei Wu, and Shengchuan Jiang \\ Key Laboratory of Road and Traffic Engineering of the Ministry of Education, Tongji University, Shanghai 201804, China \\ Correspondence should be addressed to Shengchuan Jiang; jiangsc87@gmail.com
}

Received 3 March 2014; Revised 21 May 2014; Accepted 29 May 2014; Published 30 June 2014

Academic Editor: Andy H. F. Chow

Copyright ( 2014 Yuchuan Du et al. This is an open access article distributed under the Creative Commons Attribution License, which permits unrestricted use, distribution, and reproduction in any medium, provided the original work is properly cited.

\begin{abstract}
The International Roughness Index (IRI) is a well-recognized standard in the field of pavement management. Many different types of devices can be used to measure the IRI, but these devices are mainly mounted on a full-size automobile and are complicated to operate. In addition, these devices are expensive. The development of methods for IRI measurement is a prerequisite for pavement management systems and other parts of the road management industry. Based on the quarter-car model and the vehicle vibration caused by road roughness, there is a strong correlation between the in-car $Z$-axis acceleration and the IRI. The variation of speed of the car during the measurement process has a large influence on IRI estimation. A measurement system equipped with $Z$-axis accelerometers and a GPS device was developed. Using the self-designing measurement system based on the methodology proposed in this study, we performed a small-scale field test. We used a one-wheel linear model and two-wheel model to fit the variation of the $Z$-axis acceleration. The test results demonstrated that the low-cost measurement system has good accuracy and could enhance the efficiency of IRI measurement.
\end{abstract}

\section{Introduction}

The IRI was developed in 1986 using the results of the International Road Roughness Experiment performed in Brazil in 1982 [1]. Since then, the IRI has become a wellrecognized standard for the measurement of road roughness. The main advantages of the IRI are that it is stable over time and transferable throughout the world.

The IRI is an index defined by applying the algorithm proposed by Sayers [2] to a measured realization of the longitudinal profile. The measurement of roughness is quite difficult and complex because it depends on the vehicular characteristics in addition to the actual pavement situation [3]. Moreover, the road roughness levels are readily affected by vehicle structures and driving speed. During the course of half a century of development, engineers and scientists have invented several techniques and methods for measuring road roughness. The measurement devices can be divided into four general types [4]: response-type road roughness measuring systems (RTRRMS), direct profile measurements, indirect profile measurements, and subjective rating panels. Type I devices measure the pavement roughness by correlating the RTRRMS measurements with the IRI calculated from a profile, for example, using a bump integrator or NAASRA roughness meter. Type II devices measure the road profile directly, which involves measuring each wheel track separately, for example, using a 3-meter long beam or laser road surface tester (LRST). Type III devices measure the longitudinal profile over the wavelength range of interest, for example, using a General Motors Research (GMR) profilometer. Type IV devices evaluate the pavement quality based on assessment guidance and personal experience. The common measurement methods are compared in Table 1.

Most highway agencies collect IRI data using a laser road surface tester or GMR profilometer. This equipment measures surface profiles at traffic speeds and provides excellent results for use in network analysis for pavement management systems. However, because these devices are mounted on a full-size van, automobile, or trailer, it is difficult to use them on the roadway for short periods of time. In addition, these devices are rather expensive and delicate. For these reasons, they are not effective for providing feedback to contractors' crews. Hajek et al. [5] analyzed the influence of several different factors on the IRI data that was collected 
TABLE 1: Characteristics of common road roughness measurement methods.

\begin{tabular}{|c|c|c|c|c|}
\hline Method of measurement & Principal of operation & $\begin{array}{l}\text { Measurement } \\
\text { device }\end{array}$ & Advantage & Disadvantage \\
\hline 3-Meter Long Beam & $\begin{array}{l}\text { Direct profile } \\
\text { measurement }\end{array}$ & Aluminum beam & $\begin{array}{l}\text { Simple, reliable data } \\
\text { collection }\end{array}$ & $\begin{array}{l}\text { Inefficient, } \\
\text { lower mechanization }\end{array}$ \\
\hline Level & $\begin{array}{l}\text { Direct profile } \\
\text { measurement }\end{array}$ & Level and rod & $\begin{array}{l}\text { Time-stable, } \\
\text { straightforward }\end{array}$ & Time-consuming, inconvenient \\
\hline Bump integrator & RTRRMS & $\begin{array}{l}\text { LVDT, displayer, and a } \\
\text { car/trailer }\end{array}$ & Simple, fast & $\begin{array}{l}\text { Time-instable, affected by vehicle } \\
\text { vibration, performs at the same } \\
\text { speed }\end{array}$ \\
\hline Laser road surface tester & $\begin{array}{l}\text { Direct profile } \\
\text { measurement }\end{array}$ & $\begin{array}{l}\text { Car with laser device } \\
\text { and calculators }\end{array}$ & Straightforward, efficient & $\begin{array}{l}\text { High cost of operation and } \\
\text { maintenance }\end{array}$ \\
\hline GMR profilometer & $\begin{array}{l}\text { Indirect profile } \\
\text { measurement }\end{array}$ & $\begin{array}{l}\text { LVDT, accelerometer, } \\
\text { potentiometer, and a van }\end{array}$ & Convenient, efficient & $\begin{array}{l}\text { Precise instrument required, } \\
\text { high cost of operation and } \\
\text { maintenance }\end{array}$ \\
\hline
\end{tabular}

and made several recommendations for IRI measurement. IRI measurement at the network level has become a routine practice for many road agencies in recent years. On the other hand, IRI measurement at the project level is also required, primarily for accepting or price-adjusting paving contractors' products. The development of methods for IRI measurement is a prerequisite for a pavement management system (PMS) and other parts of the road management industry.

An accelerometer is a device that measures the acceleration in one, two, or three orthogonal axes, and they are used widely in the fields of civil engineering, biology, and industry. Accelerometers can be used to measure the vehicle driving status, where they facilitate evaluations of the overall vehicle performance and response. This information can then be used to make adjustments to various vehicle subsystems, as necessary [6-8]. Accelerometers can also be used to measure seismic activity, inclination, machine vibration, dynamic distance, and speed, with or without the influence of gravity $[9,10]$.

This study focused on building a model for estimating the IRI, as well as developing an effective and low-cost system for measuring the IRI. The steps of this study, which are reflected by this organization of this paper, are as follows.

(i) Introduction to the principle of using $Z$-axis accelerometers to measure IRI.

(ii) Modeling the relationship between the variation in the in-car $Z$-axis acceleration and the IRI.

(iii) Development of a self-designed measurement system with $Z$-axis accelerometers and a GPS device.

(iv) Field testing results.

\section{The Principle of Using $Z$-Axis Accelerometers to Measure IRI}

2.1. International Roughness Index. To study the effects of the road pavement characteristics on the ride quality, we need a valid measurement of the pavement roughness and a comprehensive index to evaluate both road roughness and the ride quality, as perceived by road users. To meet this objective, a fundamental index (IRI) was established by the World Bank in 1986.

The most often employed and most useful model of a vehicle suspension system for developing a low-level controller for a vehicle suspension is the quarter-car model, in which only one quarter of the vehicle is taken into consideration. The model is two-dimensional because only movement in the $Z$ direction is taken into consideration. It consists basically of a single wheel, which is represented in the form of a spring. A general representation of a two-degree-offreedom quarter-car model is shown in Figure 1.

In this model, the sprung and unsprung masses that correspond to one corner of the vehicle are denoted by $m_{s}$ and $m_{u}$, respectively. The suspension system is represented by a linear spring of stiffness $K_{s}$ and a linear damper with a damping rate $C_{s}$, while the tire is modeled by a linear spring of stiffness $K_{t} . Y$ is the input. By drawing free body diagrams and applying Newton's Second law, we obtain the following differential equations [11]:

$$
\begin{gathered}
m_{s} \ddot{Z}_{s}+C_{s}\left(\dot{Z}_{s}-\dot{Z}_{u}\right)+K_{s}\left(Z_{s}-Z_{u}\right)=0 \\
m_{u} \ddot{Z}_{u}+C_{s}\left(\dot{Z}_{u}-\dot{Z}_{s}\right)+K_{s}\left(Z_{u}-Z_{s}\right)+K_{t}\left(Z_{u}-Y\right)=0 .
\end{gathered}
$$

We can eliminate the masses from the equations, leaving the equations in this form:

$$
\begin{gathered}
\ddot{Z}_{s}+C_{s}\left(\dot{Z}_{s}-\dot{Z}_{u}\right)+K_{1}\left(Z_{s}-Z_{u}\right)=0, \\
u \ddot{Z}_{u}+C\left(\dot{Z}_{u}-\dot{Z}_{s}\right)+K_{2}\left(Z_{u}-Z_{s}\right)+K_{1} Z_{u}=K_{1} Y .
\end{gathered}
$$

Using the response of the quarter-car model at a travel speed of $80 \mathrm{~km} / \mathrm{h}$, calculated for each point along the distance of travel, the IRI can be defined as follows [1]:

$$
\operatorname{IRI}=\frac{1}{L} \int_{0}^{L}\left|Z_{s}-Z_{u}\right| d x,
$$

where $L$ is the distance along the road on which measurement is performed. 


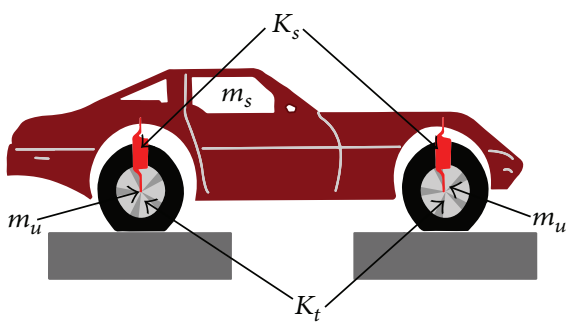

(a)

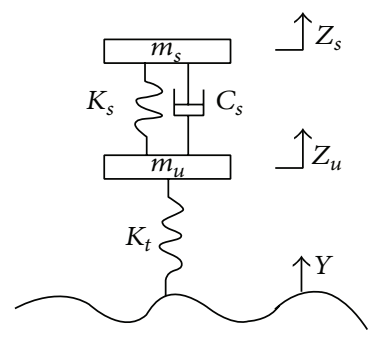

(b)

FIGURE 1: Quarter-car vehicle model. (a) Vehicle representation; (b) simplified representation.

2.2. Power Spectral Density. Power spectral density is a probabilistic method, which is a measure of the mean squared value of a random variable. In general, this method is used for random vibration analysis, which describes how the power of a signal or time series is distributed over different frequencies.

If we regard the pavement as a continuous surface, the IRI sequence of road profiles is a random phenomenon that obeys a zero-mean Gaussian distribution. This can be regarded as a stationary stochastic process. Therefore, it is appropriate to describe the pavement characteristics using the power spectral density.

Define $X(t)$ as a stationary stochastic process and $R_{x}(t)$ as its autocorrelation function, and if the Fourier transform of $R_{x}(t)$ exists, then

$$
S_{x}(\omega)=\frac{1}{2 \pi} \int_{-\infty}^{+\infty} R_{x}(\tau) e^{-i \omega \tau} d \tau .
$$

$S_{x}(\omega)$ is the PSD of $X(t), \omega$ is angular frequency, and $R_{x(\tau)}$ can be described by the inverse Fourier transform of the power spectral density:

$$
R_{x}(\tau)=\int_{-\infty}^{+\infty} S_{x}(\omega) e^{i \omega \tau} d \omega
$$

These two equations form a Fourier pair called the Wiener-Khintchine formula [12, 13].

2.3. Correlation between IRI and PSD. To evaluate the dynamic actions transmitted from a vehicle's movement on the road surface, we need to develop equations that express the physical state of the systems. According to our definition, a quarter-car model meets the condition of a LTI (linear time invariant) system. Regarding $Y(t)$ as systematic excitation, $Z_{s}(t)$ and $Z_{u}(t)$ as systematic response, based on the transmission property of LTI system, the frequency response function can be solved by means of Laplace transform [13]:

$$
\begin{gathered}
H_{Z_{s} Y}(\omega)=\frac{k_{t}\left(j C_{s} \omega+k_{s}\right)}{\Delta(\omega)}, \\
H_{Z_{u} Y}(\omega)=\frac{k_{t}\left(-m_{s} \omega^{2} j C_{s} \omega+k_{s}\right)}{\Delta(\omega)}, \\
\Delta(\omega)=\left(-m_{s} \omega^{2} j C_{s} \omega+k_{s}\right)\left(-m_{u} \omega^{2} j C_{s} \omega+k_{s}+k_{u}\right) \\
-\left(j C_{s} \omega+k_{s}\right)^{2} .
\end{gathered}
$$

According to the random process theory, $\omega=2 \pi f, n=$ $f / v$, and $x=v t$, and thus a different expression for the PSD can be obtained:

$$
S_{x}(n)=2 \pi v S_{x}(\omega) .
$$


Acceleration is the second derivative of vertical displacement. Consider

$$
\begin{gathered}
S_{a}(\omega)=\left(\frac{\omega}{v}\right)^{4} S_{x}(\omega), \\
\operatorname{IRI}=A \times \varphi_{z}=A \times \sqrt{\int_{-\infty}^{\infty}\left|H_{Z Y}(\omega)\right|^{2}\left(\frac{\omega}{v}\right)^{4} S_{a}(\omega) d w .}
\end{gathered}
$$

Therefore, it can be seen that there is a linear relationship between the IRI and the square root of pavement power spectral density function. Matlab was used to calculate the measured acceleration values. Then, the measured acceleration values were fitted to the known actual road surface roughness values. Finally, we obtained the conversion formula for the measured acceleration values and the IRI.

\section{Correction Model Based on Hybrid Sensors}

3.1. Measurement of IRI by Multiple Z-Axis Accelerometers. Because the work described in this paper was aimed at establishing a connection between the $Z$-axis acceleration (in the direction of gravity) and the IRI, we selected for testing and modeling a section of the road network of Shanghai for which the IRI had already been measured by the highway administration in 2012. A strategy of averaging multiple measurements was applied to reduce the influence of measurement errors. In the tests, the $Z$-axis accelerometers were placed flat in the car to eliminate the effect of gravity caused by the weight of the components; at the same time, the accelerometers were completely fixed inside the car, so that they would fully reflect the sprung vibration of the car. In accordance with the quarter-car model, accelerometers were fixed separately at the center of the vehicle and over the four wheels. Each link in the road network was tested four times.

3.1.1. Single-Wheel Model. The square root of each value of the power spectral density of the road-induced acceleration was calculated using Matlab, and then values that were obviously too small or large were eliminated. The averages of the square root were calculated for the left and right wheels. The results are shown in Table 2.

The square root values for the left and right wheels were calculated separately and compared with the standard IRI values. It was found that for both the left and the right wheels, there was a linear relationship between the square root value and the standard IRI. The model obtained for the right wheels was

$$
\mathrm{IRI}=2.1204 X_{r}-2.8401,
$$

where $X_{r}$ is the square root of the power spectral density of the acceleration for the right wheels on the link. $R^{2}$ is 0.9173 ; the fit of the model is very good. Similarly, the model for the left wheels was

$$
\mathrm{IRI}=1.7887 X_{l}-3.3525,
$$

where $X_{l}$ is the square root of the power spectral density of the acceleration for the left wheels on the link. $R^{2}$ is 0.8707 ; the fit of the model is again very good.
TABLE 2: Results for the left and right wheels.

\begin{tabular}{lccc}
\hline $\begin{array}{l}\text { Number of } \\
\text { links selected }\end{array}$ & $\begin{array}{c}\text { Left-wheel square } \\
\text { root value }\end{array}$ & $\begin{array}{c}\text { Right-wheel square } \\
\text { root value }\end{array}$ & $\begin{array}{c}\text { Standard } \\
\text { IRI }\end{array}$ \\
\hline 1 & 5.1634 & 4.2223 & 5.704 \\
2 & 6.3474 & 5.2826 & 9.062 \\
3 & 4.0195 & 3.2460 & 3.451 \\
4 & 3.9012 & 3.2666 & 3.874 \\
5 & 4.3624 & 3.4117 & 3.959 \\
6 & 3.5366 & 2.2714 & 2.281 \\
7 & 5.2493 & 4.1268 & 5.915 \\
8 & 4.3359 & 3.5055 & 4.838 \\
9 & 4.2007 & 3.0775 & 4.340 \\
10 & 5.0837 & 3.7241 & 5.403 \\
11 & 4.4185 & 3.1880 & 3.991 \\
12 & 4.4069 & 3.5530 & 4.290 \\
13 & 5.0762 & 4.1863 & 5.614 \\
14 & 4.9560 & 4.2084 & 5.701 \\
15 & 3.7991 & 3.2827 & 3.629 \\
16 & 4.0984 & 3.2920 & 3.963 \\
17 & 3.9900 & 3.3378 & 4.861 \\
18 & 3.0861 & 2.5950 & 2.517 \\
19 & 3.5595 & 3.3126 & 3.537 \\
20 & 3.2307 & 2.5859 & 2.697 \\
\hline
\end{tabular}

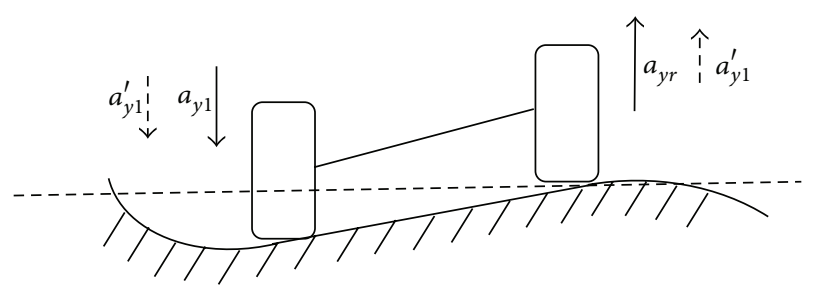

FIGURE 2: Mutual effects of left and right wheel acceleration.

3.1.2. Two-Wheel Model. During the observation process, we found that there was a relationship between the accelerations of the left and right wheels. The car body is a rigid structure, and thus when driving over the continuous surface of a pavement, if a change is produced on one side, a corresponding change will inevitably appear on the other side, as shown in Figure 2. Thus, although the tires and the suspension system can reduce the effects of the two wheels on each other, the quarter-car model used in the model described above does not provide an accurate simulation. Therefore, we can improve the accuracy of the model by considering the influences of the wheel accelerations on each other.

First, we consider the relationship between the accelerations of the left and right wheels. We used SPSS to analyze the correlations between the accelerations of the left and right wheels, and the results are shown in Table 3.

Although there is a nice relationship between the accelerations of the left and right wheels, the relationship is relatively complex, so we cannot directly establish a fitting model. However, because of the linear relationship between 
TABLE 3: Correlations.

\begin{tabular}{|c|c|c|c|}
\hline & & Right wheel acceleration & Left wheel acceleration \\
\hline \multirow{3}{*}{ Right wheel acceleration } & Correlation coefficient & 1.000 & $.851^{* *}$ \\
\hline & Significance (2-tailed) & . & .000 \\
\hline & $N$ & 31 & 31 \\
\hline \multirow{3}{*}{ Left wheel acceleration } & Correlation coefficient & $.851^{* *}$ & 1.000 \\
\hline & Significance (2-tailed) & .000 & . \\
\hline & $N$ & 31 & 31 \\
\hline
\end{tabular}

${ }^{* *}$ Correlation is significant at the 0.01 level (2-tailed).

TABLE 4: Results of multivariate linear fitting using SPSS.

(a) Model Summary

\begin{tabular}{cccccccccc}
\hline Model & $R$ & $R$ Square & $\begin{array}{c}\text { Adjusted } \\
R \text { Square }\end{array}$ & $\begin{array}{c}\text { Std. error of the } \\
\text { estimate }\end{array}$ & $R$ square change & $F$ change & df1 & df2 & Sig. $F$ change \\
\hline 1 & $.971^{\mathrm{a}}$ & .942 & .936 & .3869706 & .942 & 139.067 & 2 & 17 & .000 \\
\hline
\end{tabular}

${ }^{\text {a }}$ Predictors: (constant), right, left.

(b) ANOVA $^{\text {b }}$

\begin{tabular}{lccccc}
\hline & Sum of squares & df & Mean square & $F$ & Sig. \\
\hline 1 & & & & & \\
$\quad$ Regression & 41.650 & 2 & 20.825 & 139.067 & $.000^{\text {a }}$ \\
Residual & 2.546 & 17 & .150 & & \\
Total & $\mathbf{4 4 . 1 9 5}$ & $\mathbf{1 9}$ & & & \\
\hline
\end{tabular}

${ }^{\text {a }}$ Predictors: (constant), right, left.

${ }^{\mathrm{b}}$ Dependent variable: iri.

(c) Coefficients ${ }^{\mathrm{a}}$

\begin{tabular}{|c|c|c|c|c|c|}
\hline \multirow[t]{2}{*}{ Model } & \multicolumn{2}{|c|}{$\begin{array}{c}\text { Unstandardized } \\
\text { Coefficients }\end{array}$} & \multirow{2}{*}{$\begin{array}{c}\text { Standardized } \\
\text { coefficients } \\
\text { Beta }\end{array}$} & \multirow[t]{2}{*}{$t$} & \multirow[t]{2}{*}{ Sig. } \\
\hline & $B$ & Std. error & & & \\
\hline \multicolumn{6}{|l|}{1} \\
\hline (Constant) & -3.442 & .495 & & -6.948 & .000 \\
\hline left & .782 & .318 & .405 & 2.456 & .025 \\
\hline right & 1.300 & .369 & .581 & 3.524 & .003 \\
\hline
\end{tabular}

the square root of the power spectral density of the singlewheel accelerations and the IRI, one might guess that there is also a linear correlation between the power spectral density of the square root of the two-wheel accelerations and the standard IRI. This means that

$$
\mathrm{IRI}=a_{1} X_{l}+a_{2} X_{r}+a_{3}+\Delta .
$$

Therefore, we used multiple linear fitting of the left- and right-wheel square root values with the standard IRI.

We used the package spss17.0 to perform multiple linear regression. The regression results were as follows:

$$
\mathrm{IRI}=0.782 X_{l}+1.300 X_{r}-3.442 .
$$

$R^{2}$ is 0.942 , which satisfies the requirement for precision. Therefore, the goodness of fit for the two-wheel linear model is better than that for the one-wheel linear model, so the twowheel model can improve the fit (Table 4).

3.2. Velocity Correction. In the actual measurements, because of the limitations imposed by the conditions, the speed of the vehicle was not equal to the specified speed of $80 \mathrm{~km} / \mathrm{h}$. At the same time, the relationship between the IRI and the speed is not simply a monotonic increase or decrease, but it is very complex, and it depends on features of the pavement surface such as the waveform. Perera et al. [14] and Xiao-qing and Li-jun [11] measured the IRI values of pavements over a long period at different speeds and compared the measurements with the IRI value at the specified speed of $80 \mathrm{~km} / \mathrm{h}$. The results showed that the relationship between the speed and the IRI value is complex and it does not follow any definite proportionality relationship. The experiment showed that the 


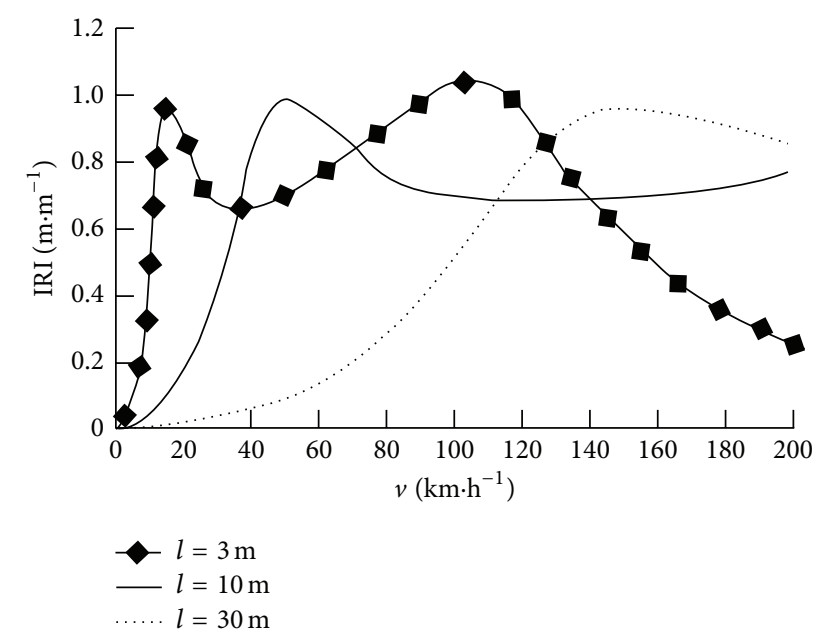

FIGURE 3: IRI values for different speeds and different waveforms $(l$ is the road wavelength).

IRI varied with the change in velocity (from $0-200 \mathrm{~km} / \mathrm{h}$ ) and wavelength (divided into long wave $l=30 \mathrm{~m}$, medium wave $l=10 \mathrm{~m}$, and short wave $l=3 \mathrm{~m}$ ), as derived in Figure 3.

Because of the nonlinear relationship between IRI value and speed, the variation of speed during the measurement process has a large influence on the IRI measurement. Therefore, when $Z$-axis accelerometers are used to measure the IRI, a modification for speed is required. At the same time, it is also important in an IRI measurement to consider the length of road over which measurement is performed and the start and end points. Consequently, we chose a GPS system to allow us to perform modification for speed and so on.

To analyze the influence of speed on the results of the model, we chose an experimental road with light traffic where the traffic speed could reach $80 \mathrm{~km} / \mathrm{h}$. It has been found from field tests that when the vehicle speed reaches $60 \mathrm{~km} / \mathrm{h}$, certain areas of the vehicle tire are not in contact with the road pavement. This violates our earlier assumption that the distance between the tire and pavement is zero. Therefore, in our experiment, we chose speeds of $20,30,40,50$, and $60 \mathrm{~km} / \mathrm{h}$ on the test road, measured the $Z$-axis acceleration of the car wheels, and calculated the IRI for the link for each speed separately using the model. If the results were consistent, this would indicate that the model did not depend on the measurement speed. If not, we could modify the model by fitting the calculated results to the vehicle speed. Because the same model was used to calculate the IRI value in each case, the different IRI values for different speeds were related only to the power spectral density values of the acceleration. Therefore, we fitted the power spectral density and speed directly. The results are shown in Table 5 .

When the power spectral density value and the speed $v$ are fitted, the model is

$$
\text { PSD }=0.0263 v^{2}+0.6027 v .
$$

$R^{2}$ is 0.9991; this model has a very good fit.

Using this model, we can consider the reason why different speeds will lead to different results of the calculation.
TABLE 5: Values of power spectral density for different speeds.

\begin{tabular}{lccccc}
\hline Speed $(\mathrm{km} / \mathrm{h})$ & 20 & 30 & 40 & 50 & 60 \\
\hline $\begin{array}{l}\text { Power spectral } \\
\text { density }\end{array}$ & 20.9189 & 41.7322 & 68.044 & 115.6324 & 130.4095 \\
\hline
\end{tabular}

The spatial frequency (in units of $\mathrm{m}^{-1}$ ) that characterizes the collection frequency of the numerical data is the number of samples per meter. Because the frequency at which the sensor reads data is constant, the spatial frequency of the sequence of acceleration data is related only to the speed. At the same time, because of the small variation of the measuring speed, a quadratic fitting curve is better than a quartic curve. As a result, after modification for the effect of speed, the IRI model is

$$
\text { IRI }=0.782 \alpha X_{l}+1.300 \alpha X_{r}-3.442,
$$

where $\alpha$ is the correction coefficient for the effect of speed, given by

$$
\alpha=\frac{1}{\sqrt{0.0003865 v^{2}+0.0009125 v}} .
$$

\section{System Design}

According to the fitting model we constructed in Section 3, we developed a coupled system for measuring the IRI. The system comprised two sections: a hardware platform and a software system.

4.1. Description of the Hardware Platform. The hardware platform was used to collect $Z$-acceleration data for pavements, as well as GPS data, which was transmitted to the software system. The hardware platform comprised the following (Figure 4):

(i) Z-axis accelerometer sensors, type MMA8451Q

(ii) GPS module, type Ublox NEO-6M

(iii) ZigBee modules

(iv) Microcontroller units (MCU), type TC12C5608AD.

The $Z$-axis accelerometer is a triaxial, intelligent, lowpower, mechanical acceleration sensor. This type of sensor can access data from both a low-pass filter and a high-pass filter and therefore greatly reduces the peak data requirements for data analysis and achieves faster data transfer. The sample frequency of the accelerometers was set to 0.1 second, which made the pavement appear more like a continuous surface and this ensured the data processing efficiency. The GPS module contained an integrated audio frequency chip, a baseband chip, and a core CPU. The core controller could connect multiple $Z$-axis gravity accelerometers and GPS devices. The positional accuracy of GPS is 1 meter, which is adequate for field experiments and road tests.

4.2. Description of the Software Platform. The software system was used to obtain real-time data from hardware devices and it comprised two main components (Figure 5) as follows. 


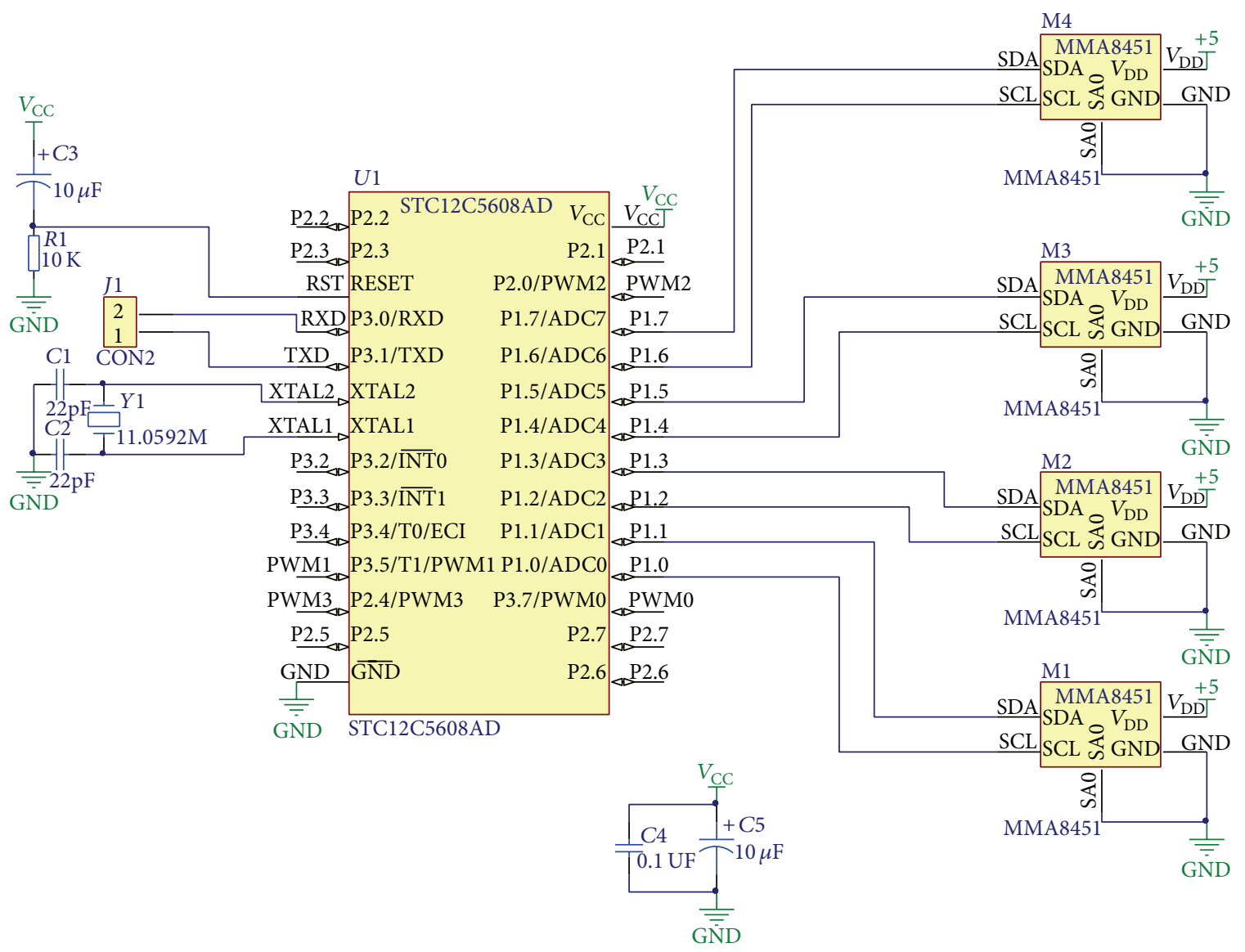

FIGURE 4: Schematic diagram of the system circuit.

(i) Data acquisition software based on C\# for obtaining the acceleration rates from various devices and storing these data.

(ii) A Matlab GUI data processor (based on Matlab GUI) for calculating the IRI (or RQI) using the model constructed above.

4.3. Description of the System Design. The system could record real-time $Z$-axis accelerations in different pavement conditions at various frequencies, as well as using different parameters, such as those used to describe the driving conditions (Figure 6).

The system design had a two-tier construction. The accelerometers obtained the real-time acceleration and transmitted them to the data acquisition software via a Zigbee module. GPS was also received as geographic information from satellites and transmitted to the software via Bluetooth. When the data flowed into software tier, the acquisition software could match the GPS information and acceleration with the time data, as well as reading the real-time changes based on the wave patterns and locating the position we measured on the e-map. The data obtained from the data acquisition software were used by the Matlab GUI data processor. The processor removed any abnormal data based on residual analysis and we then used the model described above to calculate the PSD of pavements and to evaluate the IRI value.

\section{Field Test}

To verify the accuracy of the model, we used the above measurement system to perform a field test. The accelerometers were placed flat and fixed completely inside the vehicle, so they fully reflected the sprung vibration of the vehicle. As described in Section 3, the accelerometers were fixed separately over the wheels. Given that the practical tracks on which both the front and back wheels travel were basically the same, it was not necessary to collect acceleration data repeatedly. By contrast, the tracks of the left and right wheels were totally different, so their mutual effects could not be neglected. At the same time, the back wheels were affected less by the engine, so the accelerators were set immediately above the right back wheel and left back wheel in the test car.

Eight typical roads in Shanghai, for which the IRIs were provided by the Shanghai Highway Administration Bureau, were selected for the field test. The specific method employed was as follows.

(i) We confirm the stake mark of the testing origin and destination and recorded the positional data. 


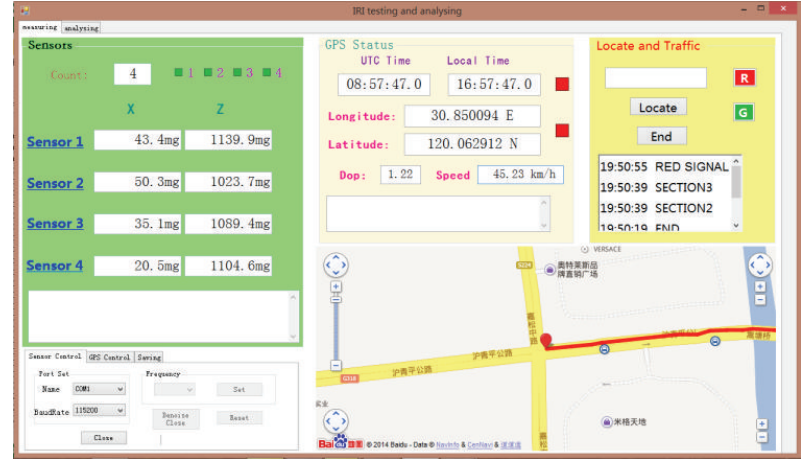

(a)

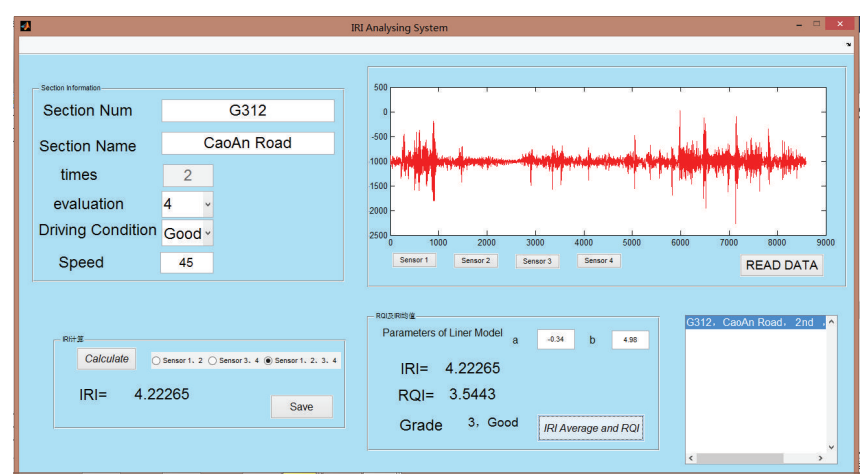

(b)

FIgUre 5: (a) Data acquisition software, (b) Matlab GUI data processor.

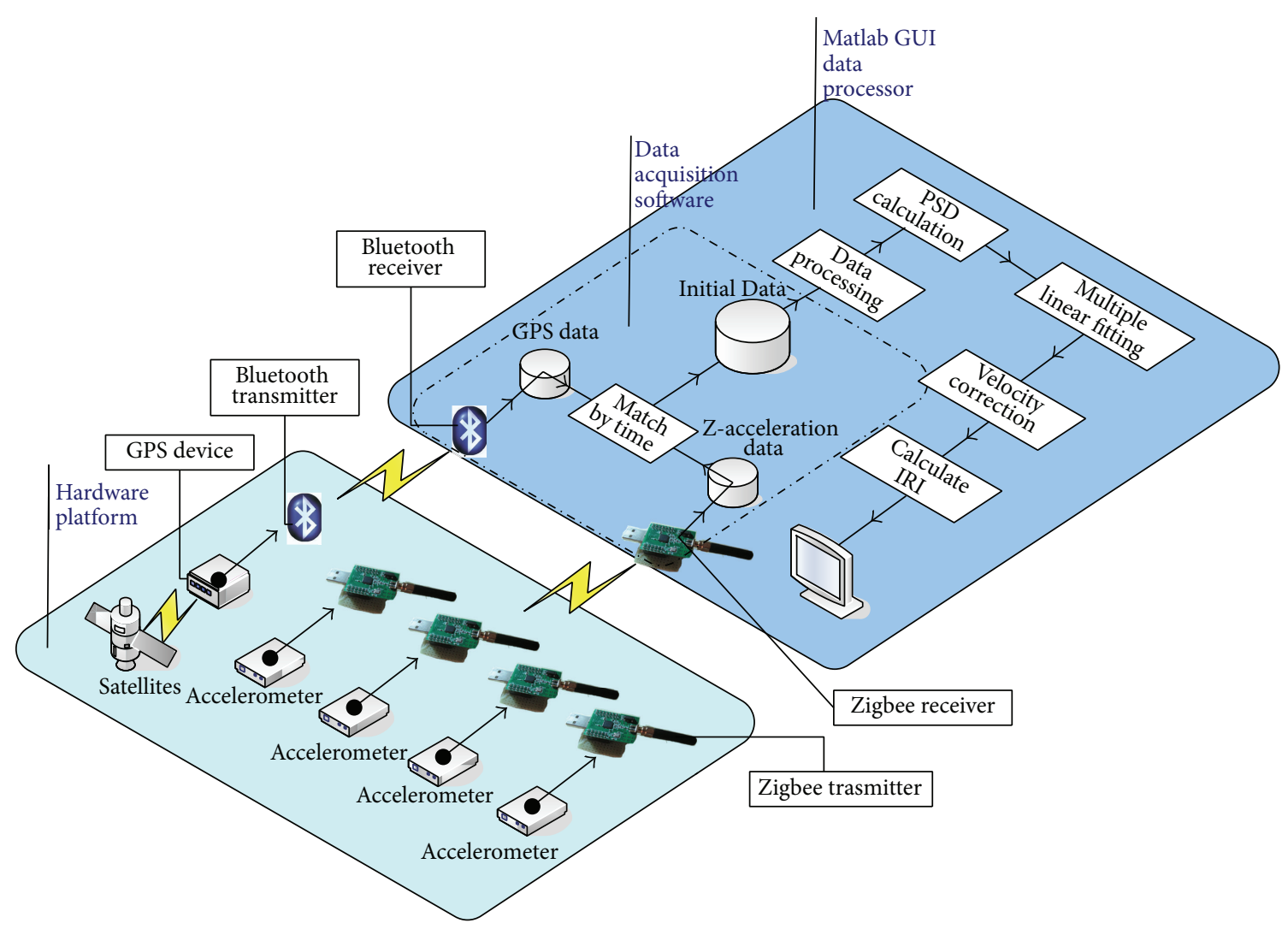

FIGURE 6: Schematic diagram of the measurement system.

(ii) The experimental car with the measurement system was used to acquire the vertical acceleration (accuracy: $0.01 \mathrm{mg}$, frequency: $10 \mathrm{~Hz}$ ) and GPS (accuracy: $1 \mathrm{~m}$, frequency: $1 \mathrm{~Hz}$ ) at about $60 \mathrm{~km} / \mathrm{h}$, where data were recorded for both the left and right wheels.

(iii) The acceleration data were imported into Matlab GUI, before calculating the approximate IRIs of these roads using the linear fitting model.

We selected the measurement data for links 21 to 28 as the input of the model to calculate the IRI. We then calculated the relative error between the approximate IRI obtained from the model and the actual IRI (detected by the vehicle bearing road laser profilometer; Highway Administration of Shanghai, 2012) to test the suitability of the model. The results are shown in Table 6.

When we used the model presented in Section 3 to fit the $Z$-axis acceleration to the IRI, the results showed that the relative error of the approximate IRI value was lower than $15 \%$ and the standardized residual was between -2 and +2 . Therefore, this model can meet the needs of the majority of pavement measurements. Thus, this method based on $Z$-axis accelerometers and GPS devices is feasible for measuring the IRI. 
TABLE 6: Approximate values of the IRIs obtained using the model.

\begin{tabular}{lcccccc}
\hline Link number & $\begin{array}{c}\text { Right-wheel square } \\
\text { root value }\end{array}$ & $\begin{array}{c}\text { Left-wheel square } \\
\text { root value }\end{array}$ & Actual IRI & Approximate IRI & $\begin{array}{c}\text { Relative error } \\
(\%)\end{array}$ & $\begin{array}{c}\text { Standardized } \\
\text { residual }\end{array}$ \\
\hline 21 & 3.0182 & 4.3766 & 3.9041 & 4.109 & 4.98 & 0.78773 \\
22 & 3.7904 & 4.3842 & 4.9140 & 4.566 & 7.61 & -0.76443 \\
23 & 3.4982 & 4.0119 & 4.2430 & 4.292 & 1.14 & 0.350071 \\
24 & 3.1138 & 3.9016 & 3.6570 & 4.086 & 10.49 & 1.416846 \\
25 & 4.4060 & 5.4115 & 6.5001 & 6.137 & 5.92 & -0.80682 \\
26 & 5.0087 & 5.5317 & 6.4629 & 6.020 & 7.36 & -1.03084 \\
27 & 5.7322 & 4.2199 & 3.9496 & 4.315 & 8.46 & 1.238302 \\
28 & 4.9631 & 4.3613 & 4.4039 & 3.904 & & 12.82 \\
\hline
\end{tabular}

\section{Conclusions}

To address the problems of pavement roughness measurement, we established an IRI estimation model based on regression analysis. Based on the multiple linear fitting model and velocity correction model, we developed a coupled system that can record the real-time $Z$-axis acceleration in different pavement conditions, at different times, and with different values for various other parameters.

The variation in the in-car $Z$-axis acceleration caused by road roughness can be regarded as a combination of the vibration produced by different mechanical components, and thus the vertical acceleration is strongly correlated with the IRI. The quarter-car model was a LTI system and the mean squared value of the power spectral density could represent the equivalent amplitude of signals, which can represent the size of the signal amplitude, and thus we used a regression method to model the variation in the $Z$-axis acceleration and the IRI. We used the power spectral density sequence of the $Z$-axis acceleration to model the IRI. An innovative feature of the measurement process was that multiple local accelerations were considered in order to improve the goodness of fit of the model.

Because the relationship between the IRI value and the speed is nonlinear, variation of the speed during the measurement process has a large influence on the measured IRI value. The length of road along which the measurement is performed and the start and end points are also important in this measurement, so we used a GPS device to allow us to take account of speed. The influence of speed on the results of the model was analyzed, and we then put forward the concept of a speed correction coefficient to improve the reliability of the model.

We used the IRI evaluation model and system to measure the IRI of some typical roads in Shanghai. When our model was used to fit the $Z$-axis acceleration to the IRI, the results showed that the relative error of the estimated IRI was less than $15 \%$.

\section{Conflict of Interests}

The authors declare that there is no conflict of interests regarding the publication of this paper.

\section{Acknowledgments}

This work was based on the results of a research project, which was supported by a research Grant no. 2012AA112402 from the Ministry of Science and Technology of the People's Republic of China and a research Grant no. 11511501100 from Shanghai Science and Technology Committee. The work of the last author was supported by Program for Changjiang Scholars and Innovative Research Team in University and Shanghai Pujiang Program (11PJD022). The authors take sole responsibility for all views and opinions expressed in this paper.

\section{References}

[1] M. W. Sayers, T. D. Gillespie, and W. D. Paterson, "Guidelines for the conduct and calibration of road roughness measurements," World Bank Technical Paper 46, The World Bank, Washington, DC, USA, 1986.

[2] M. W. Sayers, "On the calculation of IRI from longitudinal road profile. TRB Paper No. 95 0842," in Proceedings of the 74th Annual Meeting on Transportation Research Board (TRB '95), Washington, DC, USA, 1995.

[3] J. R. Prasad, S. Kanuganti, P. N. Bhanegaonkar, A. K. Sarkar, and S. Arkatkar, "Development of relationship between roughness (IRI) and visible surface distresses: a study on PMGSY roads," Procedia-Social and Behavioral Sciences, vol. 104, pp. 322-331, 2013.

[4] M. W. Sayers, T. D. Gillespie, and A. V. Queiroz, "The international road roughness experiment. Establishing correlation and a calibration standard for measurements," Tech. Rep. WTP45, 1986.

[5] J. J. Hajek, T. J. Kazmierowski, and G. Musgrove, "International roughness index as a measure of customer satisfaction ," in Proceedings of the Annual Meeting of the Transportation Association of Canada, Victoria, Canada, 1995.

[6] T. J. Kwon, M. Gerla, V. K. Varma, M. Barton, and T. R. Hsing, "Efficient flooding with passive clustering-an overhead-free selective forward mechanism for ad hoc/sensor networks," Proceedings of the IEEE, vol. 91, no. 8, pp. 1210-1220, 2003.

[7] H. Sabbineni and K. Chakrabarty, "Location-aided flooding: an energy-efficient data dissemination protocol for wireless sensor networks," IEEE Transactions on Computers, vol. 54, no. 1, pp. 36-46, 2005. 
[8] J. E. Jefferies, R. W. DeMay, and G. L. Lachinyan, "Rental/carshare vehicle access and management system and method," U.S. Patent Application 13/830,754, 2013.

[9] T. Dishongh, F. Guilak, and M. Morris, "Apparatus for monitoring physiological, activity, and environmental data," U.S. Patent Application 11/641,973[P], 2006.

[10] A. Prakash, B. N. Sharma, and T. J. Kazmierowski, "Investigation into observational variations in pavement condition survey," in Proceedings of the 3rd International Conference on Managing Pavements, vol. 2, pp. 290-301, Washington, DC, USA, 1994.

[11] Z. Xiao-qing and S. Li-jun, "Relationship between international roughness index and velocity of quarter car," Journal of Tongji University, vol. 33, no. 10, pp. 1323-1327, 2005.

[12] P. Stoica and R. L. Moses, Introduction to Spectral Analysis, Prentice-Hall, Upper Saddle River, NJ, USA, 1997.

[13] X. Zhou, L. Yan, and L. Sun, "Study and validation of the relationship between international roughness index and power spectral density," China Civil Engineering Journal, vol. 40, no. 1, pp. 99-104, 2007.

[14] R. W. Perera, C. Byrum, and S. D. Kohn, Investigation of Development of Pavement Roughness, 1998. 


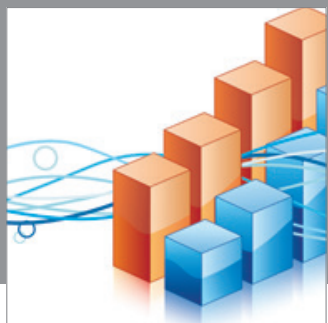

Advances in

Operations Research

mansans

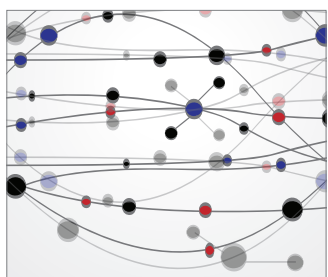

The Scientific World Journal
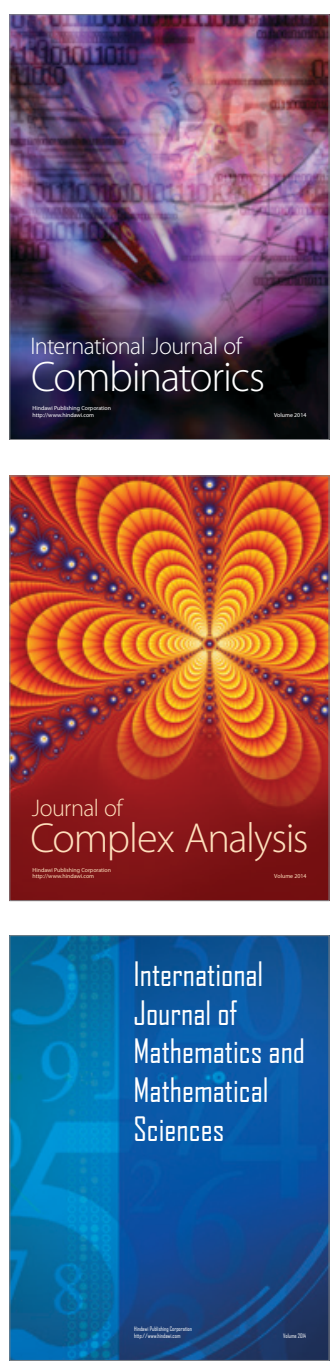
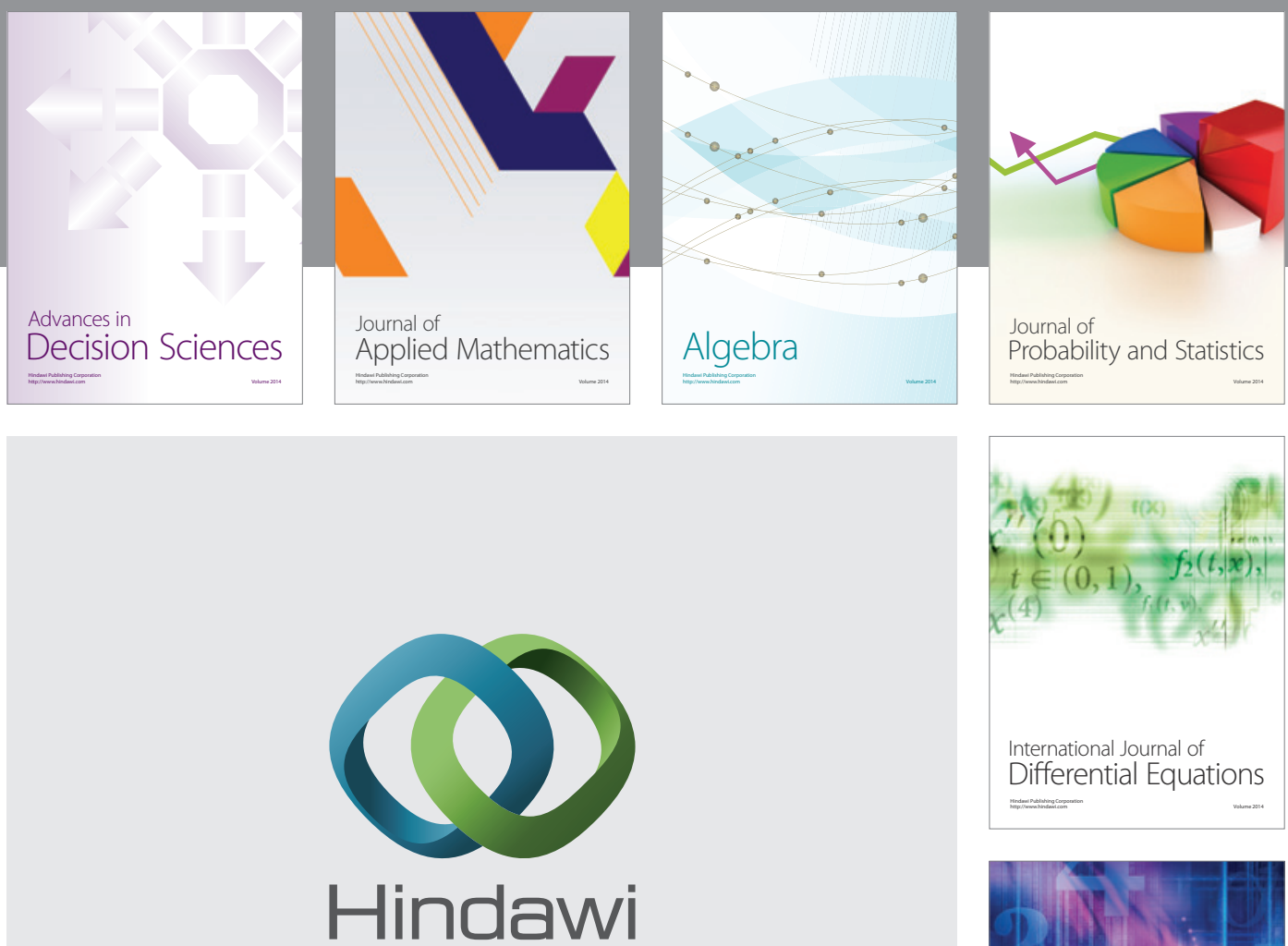

Submit your manuscripts at http://www.hindawi.com
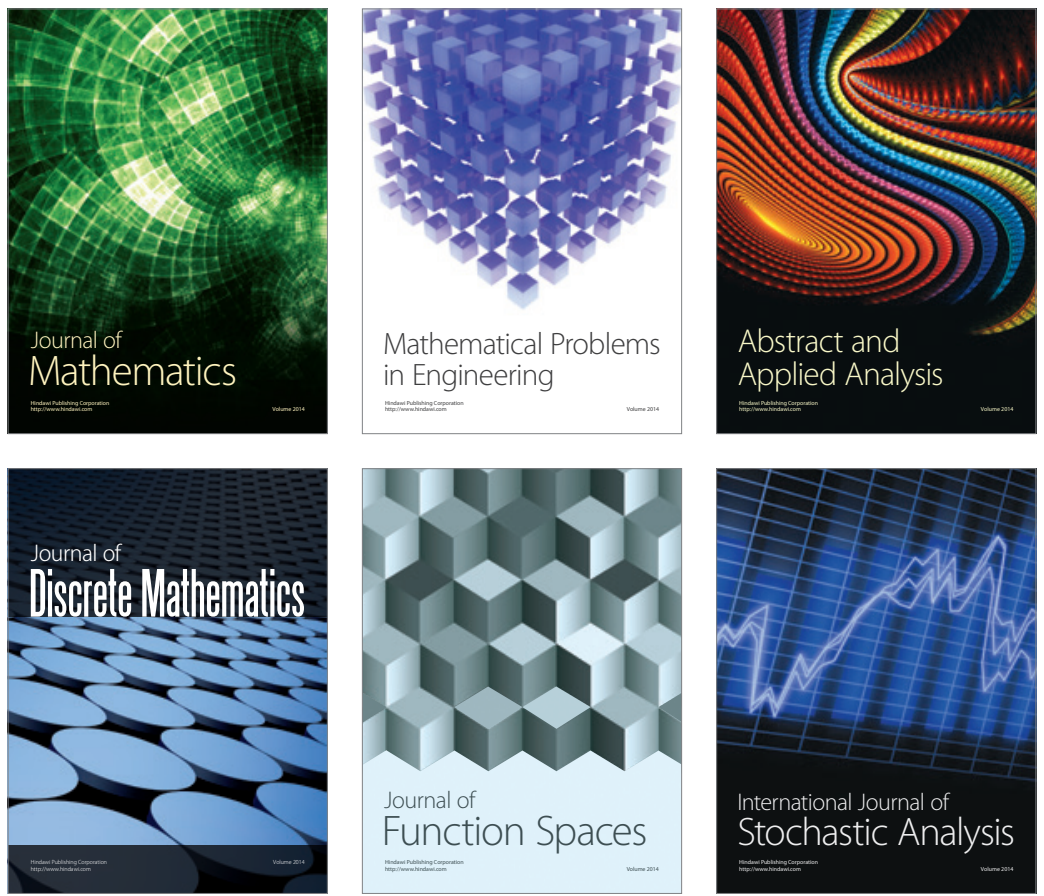

Journal of

Function Spaces

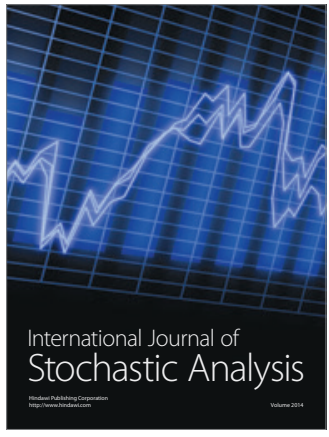

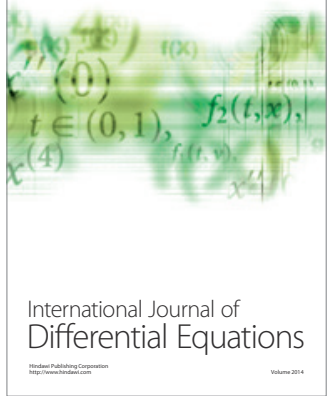
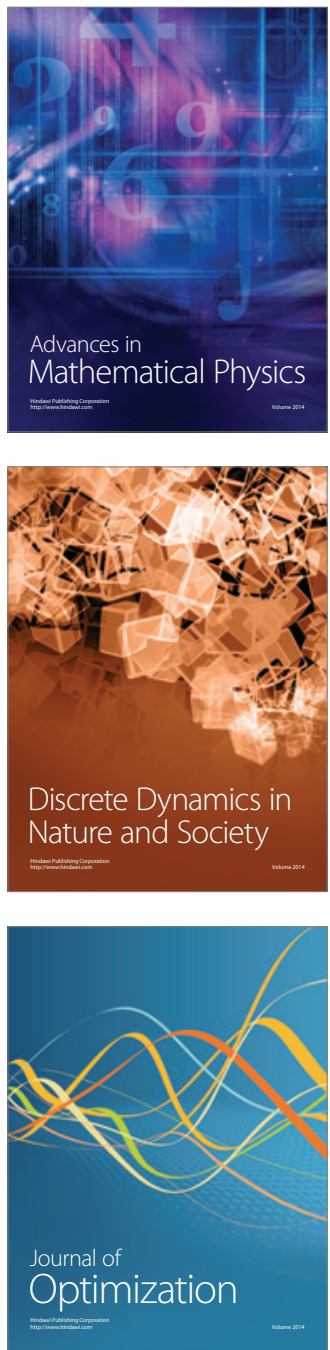